\section{ON THE RELATIONS OF TUBERCLE BACILLI TO OTHER BACTERTA RESISTANT TO ACIDS AND TO ACTINOMYCES. ${ }^{1}$}

\section{BY DR. ALFRED MOELLER.}

Discoveries that have been made in recent years of tubercle-producing bacilli resistant to acids and similar micro-organisms have made it impossible to diagnose the tubercle bacillus by the aid of the microscope alone. Before these discoveries were made it had been customary to call every genuine bacillus that was resistant to acids and alcohol a tubercle bacillus. It is true that what was known of the similar behaviour of the lepra bacillus with respect to colour reaction already showed that the tinctorial behaviour of the tubercle bacillus was to be regarded as dependent on its other biological qualities, that in course of time it might be possible to find other bacteria which were equally resistant to acids and alcohol and with the same peculiarities with regard to colour reaction as the tubercle bacillus.

There has been a good deal of discussion as to the nature of this colour-reaction and its relation to the real substance of the bacteria. Koch himself says that from a diagnostic point of view the peculiar colour-reaction of tubercle bacilli is at any rate of value, but that it is a great mistake to think that the etiological significance of tubercle bacilli stands and falls with its specific colour reaction. Recently Klein, and later Marmorek, have shown that quite young tubercle bacilli are not resistant to acid and alcohol. Narmorek attributes this to the fact that young tubercle bacilli are not yet covered with that fatty and waxy envelope which on the one hand prevents the ordinary basic pigments from coming into contact with the protoplasm of the tubercle bacillus, and on the other hand prevents acids and alcohol from decolourising them when once stained. Klein thinks that the resistance to acids of the tubercle bacilli depends on the production of chemical substances on the part of the bodies of the bacilli. These, in the young tubercle bacilli, are wanting, and therefore they are susceptible to acids. Borrel, by experiments, sncceeded in taking away the resistance to acids and alcohol of the tubercle bacilli. Under the protracted action of warm xylol a growth-like mass conld be removed from the tubercle bacilli, which was resistant to acids and alcohol, whilst the tubercle bacilli thus treated had lost these qualities, though they were still capable of producing tubercle. Whatever may cause this resistance to acids in the tubercle bacillus it is quite justifiable to attribute the same tinctorial behaviour of the other bacteria, which are resistant to acids, to a like cause. But this mutual colour reaction is only the outer band that keeps the whole together; what is of much greater significance is, that there is more or less close resemblance among the bacteria, and with the tubercle bacillus, with respect to morphology and pathogenesis.

Bacteria resembling the tubercle bacillus, and known to us for years, are the lepra bacillus, smegma bacillus, and the organism of avian tuberculosis. The bacillus of leprosy was first described, in 1877, by Armauer Hansen. It was found in leprous tubercles. It resembles the tubercle bacillus in form, but is generally of more uniform length, and shorter, It stains more readily than the tubercle bacillus-e.g., it stains with aqueous fuchsin solution, even at room temperature, which the tubercle bacillus will not do. Neisser, who has done much to make the bacillus of leprosy more generally known, gives Weigert's method of granule staining as the differential stain. Neither Hansen nor Neisser have succeeded in obtaining pure cultures. Bordoni-Uffreduzzi, in 1887 , is alleged to have succeeded in cultivating from the marrow of the bones of a leper a micro-organism resembling the tubercle bacillus, even as regards resistance to acids. The cultures were not maintained. Cultivated bacteria from the organs of lepers, described rather later by Babes, and still more recently by Czaplewski, differ from the genuine bacillus of leprosy in their incomplete resistance to acids.

A paper communicated to the British Congress on Tuberculosis. tiou III., Pathology, including Bacteriology.
Both authors maintain that the bacteria cultivated by them resemble the bacilli of diphtheria. In any case it is very doubtful whether these bacteria cultivatel from leprosy are the genuine bacillus lepra. The smegma bacillus was first discovered by Tavel and Alvarez in 1885, in the normal preputial smegma, and also in the secretion of the outer skin, particularly where a collection of epithelium may occur, as in the anal and vulvar region, in the fold of the groin. or between the toes. With respect to differential diagnosis, especially in reference to urogenital tuberculosis, the smegma bacillus is undonbtedly of greater importance.

As a micro-organism resistant to acids which has long been known, I may also mention the organism of avian tuberculosis. It differs from the organism of tuberculosis in mammals in the appearance of the cultures and the temperature conditions. Bacilli of tuberculosis of mammals will not thrive at $42^{\circ} \mathrm{C}$., whilst bacilli of avian derivation will thrive at this and even higher temperatures. Fischel, who worker under Huppe's directions, says that both micro-organisms are of one and the same kind as regards nutritive media. In consequence of the different physiological nutritive media of the colder mammalian bodies on the one hand, and the warmer avian bodies on the other, a distinction has arisen between the two kinds. By artificial cultivation Fischel succeeded in bringing about approximation in outer qualities between the two bacteria: he succeeded in getting the organism of tuberculosis in mammals accustomed to a higher temperature, and in given nutritive media he got a resemblance in the appearance of the cultures, but as regards pathogenesis he could not transfer one to the other. Fischel says that he was able, with the organism of avian tuberculosis, to bring about a general tuberculosis in a guinea-pig, but the cultures derived from the organs of this animal were not identica? with those of avian tuberculosis. In my own similar experiments on animals I got the same results. T'uberculosis in cold-blooded animals is in the same way to be regarded as a modification of the tuberculosis in mammals. Bataillon and Terre succeeded in cultivating tuberculosis in mammals and birds by means of passing it through the body of a frog at room temperature. Lubarsh was able to modify tuberculosis in mammals by passage through the body of a frog, so that cultures taken from the spleen of a frcg grew at a temperature of as much as from 28 to $30^{\circ}$. Dubord also cultivated cultures taken from fish inoculated with mammalian tuberculosis which also thrived at room temperature. I was able to produce cultures from the spleen of a slowworm inoculated with sputum containing tubercle bacilli, which flourished at $20^{\circ}$, but which ceased to grow at a temperature of $30^{\circ}$ and over. The cultures resembled in appearance those of avian tuberculosis. I have not yet succeeded in obtaining cultures which got accustomed agajn to a temperature of $37^{\circ}$, even after passage through warmblooded animals.

Recently it has been possible to demonstrate a series of micro-organisms in the outer surroundings of man which in many respects resemble the tubercle bacillus. Tubercle bacilli were found in such appalling frequency in butter and milk that it led to an inquiry as to whether the genuine tubercle bacillus was really always found. Petri and Rabinowitsch were the first to make such experiments. Both succeeded in getting a bacillus resistant to acids and alcohol from butter, that was not the tubercle bacillus. The micro-organisms described by these two authors are so materially alike that they are both generally described as the Petri-Rabinowitsch butter bacillus.

I have lately cultivated from milk in pure culture a microorganism similar to the tubercle bacillus which does not differ materially from the grass bacillus II. All bacteria resistant. to acids cultivated from milk and its derivatives show a great resemblance to the grass bacillus. Taking into consideration the habitat of the latter-namely, cattle fodder-we are certainly justified in regarding the milk and butter bacilli as varieties of the grass bacillus. Such differences as there are-and these are very slight-may be explained by the passage through the bodies of animals. I could prove the presence of the grass bacillus in grasses much used for cattle fodder and could cultivate them in pure cultures. As they were first discovered on timothy grass (phleum pratense) I have named them timothy bacilii. The timothy bacillus has the shape of a slender little rod, sometimes slightly curved. Microscopically it is often impossible to distinguish it from the tubercle bacillus. Like the latter if often contains deeply stained granules; 
oval unstained patches are found in its interior; it divides into branches, and sometimes has club-shaperl swellings at one end. In the decolourising solution, as woll as in sections with the ordinary staining methorls, it behaves exactly like the tubercle bacillus. The timothy bacillus grows best at incubation temperature, but it thrives badly at room temperature. It thrives on all usual nutritive media. After 36 hours, even at incubation temperature, patches of colonies are distinctly seen. The cultures generally vary considerably from those of the tubercle bacillus, but a similarity is sometimes attained if the timothy bacillus, after several passages through the bodics of animals, is cultivated at a uniform temperature of $37^{\circ}$. It then tencls to become more like the tubercle bacillus in its slow growth. As regards pathogenesis, the timothy bacillus produces in ouinea-pigs almost the same pathological changes as the Petri-Rabinowitsch butter bacillus. It has a different effect on rabbits. In them, if the timothy bacillus is injected into the veins and arteries of the animal, changes are produced which it is difficult to distinguish from true tuberculosis. "There is also a variety of the grass bacillus, a micro-organism resistant to acids, found in the excreta of animals, and therefore called the "manure bacillus." I found it in a manureheap which had lain for months, and also in the fresh excrementa of cows, donkeys, and other herbivora. 'The manure bacillus bears a morphological and tinctorial semblance to the timothy bacillus; in growth of cultures and in pathogenesis it also resembles the grass bacillus II.

In this résumé I prefer to pass over the lepra and smegma bacillus on account of their relatively rare occurrence, and Because so little is known of their cultural growth, and the avian and cold-blooded mammalian tubercle bacillus on account of their unimportance as regards differential diagnosis. We are, therefore, left with grass bacilli as a primitive form, with its varieties, milk and butter bacilli, and manure bacillus. With respect to colour reaction they all, with slight deviations, behave like the tubercle bacillus. 'l'he same may be said of their morphology. Though in form the different species vary more or less, it is often impossible microscopically, under certain conditions, to distinguish them from the tubercle bacillus, and the tubercle bacillus itself Taries according to the nutritive medium that it finds. I have made innumerable examinations of sputum in which I have seen the rods somewhat shorter, sometimes longer, sometimes thicker, and sometimes thinner. B. Fränkel first drew attention to the fact that the tubercle bacillus in the Horid form of tuberculosis generally took the form of short rods. "Ihose forms which deviate from the ordinary bacillus shape, such as rodlets, ramifications. keel-shaped swellings, as well as oral patches in the middle of the bacilli which will not stain, deeper-dyed granules, \&c., are met with in the tubercle bacillus, as well as in other bacteria resistant to acids. In cultural growth, howerer, the grass bacilli differ materially from the tubercle. In the first place, in the appearance of the cultures; even when now and then a more or less close resemblance has been attained through the methods of cultivation the tuberculosis culture shows such characteristics uniformly, so that it is easy to ristinguish it from all the others. Then it stands apart in its subtle behaviour with regard to temperature. Whilst other bacteria resistant to acids thrive at room temperature the tubercle bacillus requires incubation temperature. "The position of the tubercle bacillus is unique with respect to rits excessively slow growth. Other bacteria resistant to acids form visible colonies at the latest after 24 hours at incubation temperature, whilst the earliest moment that growth has been observed in the tubercle bacillus is only after several davs, even under the most favourable conditions of frequent transplantation on specially chosen nutritive media. 'This exceptional behaviour of the tubercle bacillus is very valuable from a differential diagnosis point of view. Several authors isay that cometimes bacilli resistant to acids were found in the sputum in morbid conditions of the respiratory organse.g., in gangrene of the lung - which, on closer examination, alid not prove to be genuine tubercle bacilli. Fränkel and Pappenheim proved this by dissection; Rabinowitsch proved conclusively, by pure culture of the bacteria, that it was probably a variety of their butter bacillus. I have frequently found these pseudo-tubercle bacilli not only in sputum from the lungs, but also in mucus from the nose and pharynx, coating of the tongue, sordes on the teeth, and secretion on the tonsils.

In those cases in which physical symptoms are entirely absent, and the suspicion of tuberculosis is based on the existence of bacilli resistant to acids in the secreticn of the respiratory organs, the diagnosis may be confirmed by the following simple method, based on the slow growth of the tubercle bacillus and its peculiar temperature requirements. The secretion in question is mixed with nutritive bouillon and kept at about $30^{\circ}$. If there is a visible increase in the bacteria resistant to acids it is certain that it is not the genuine tubercle bacillus. Sometimes in the tubercle bacillus the sputum, mixed with certain nutritive media, increases at incubation temperature. This proliferation, due in all probability to the importation of globulin-like substances from the body, is, however, exceedingly small and ceases altogether after, at the latest, 48 hours ; whilst in the pseudo-tubercle bacilli a persistent further proliferation takes place at $30^{\circ}$. There was no pathogenic effect noticeable either in the bacteria isolated by Rabinowitsch in gangrene of the lung or in those found by me in mucus from tonsils, nose, and pharynx.

Different occurrences in practical life bring out the differentiation of pseudo-tubercle bacilli from genuine tubercle bacilli even more than at the sick-bed. I should like to give but two chief examples. For years two of our most important articles of food-milk and butter-were looked upon with lively horror because all the bacteria resistant to acicls they contained were supposed to be tubercle bacilli. The isolation of manure bacillus showed the untenableness of the conclusion that the proof of bacteria resistant to acids in the excrementa of cattle was undoubtedly due to the existing bovine tuberculosis in the animals concerned. As regards pathogenesis, all bacteria resistant to acids have this in common, that they cause a tuberculous-like disease in the usual animals experimented on, the genuine tubercle bacillus always, but the pseudo-tubercle bacillns only in a limited number of cases and under certain conditions. The whole appearance of pseudo-tuberculosis in the bodies of animals bears macroscopically frequently a striking resemblance to genuine tuberculosis. But in the tubercles themselves there is a visible difference; whilst the genuine tubercles are of a solid proliferating kind, the pseudotubercles are of a more inflammatory character with tendency to abscess formation. The typically histological condition of genuine tuberculosis giant-cells, epithelioid cell nests, caseation, is only met with in pseudo-tuberculosis in very rare cases, when under given conditions, the bacilli are introduced into the bodies of animals. Another peculiarity of the tubercle bacillus I should still like to refer to. If, together with butter, it is injected intra-peritoneally into animals typical tuberculosis does not result, but peritonitis sets in accompanied by severe formation of induration, exactly the same as follows the injection of pseudo-tubercle bacilli and butter.

Though the obvious resemblances between bacteria resistant to acids and the tubercle bacillus are so many and so great, they only produce an outward relationship. As far as the real, I might say, inner being of the tubercle bacillus is concerned, its pathological effect on the human organism, its etiological significance in tuberculosis, it occupies a perfectly unique position among bacteria resistant to acids.

\section{EXAMINATION OF CARCASSES IN CASES OF CATTLE TUBERCULOSIS. ${ }^{1}$}

Illustrated by 100 Lantern Slides taken from Photographs obtained at the Carlisle Public Slaughter-house.

\section{BY WILLIAM BROWN, F.R.C.S. EDIN.}

OF the numerous functions which a medical officer is called upon to perform, perhaps there is none having a greater degree of anxiety and responsibility attached to it than the examination of cattle carcasses as to their wholesomeness for human food. Apart from cases where litigation is in question the medical officer has frequently a difficult and delicate duty to perform. On the one hand, he has to protect the consumer against meat of a doubtful charactor, and, on the other hand, due consideration is to be paid to the owner, who may have taken every possible care to secure what appeared to be a perfectly healthy animal.

I A paper communicated to the British Congress on Tuberculosis. Section III, Pathology including Bacteriology. 